\title{
Intestinal Maturation in the Rat: the Effect of Glucocorticoids on Sodium, Potassium, Water and Glucose Absorption
}

\author{
RAYMOND MENEELY AND FAYEZ K. GHISHAN ${ }^{(16)}$ \\ Pediatric Gastroenterology, Vanderbilt Medical Center, Nashville, Tennessee, USA
}

\begin{abstract}
Summary
The effect of glucocorticoids on the intestinal transport of water, electrolytes, and glucose in the infancy period is not known. Therefore, we studied the effect of parenteral glucocorticoids on intestinal transport of water, electrolytes and glucose in suckling rats with an in vivo single pass perfusion technique. Glucocorticoids enhanced significantly net sodium transport only in the colon segments compared to controls. Net sodium transport in the small intestinal segments was similar in glucocorticoid and control groups. Similar to adult animals, glucocorticoids enhanced glucose transport in the ileum, but not in jejunum segments. Net potassium absorption was decreased five-fold in jejunum segments and reversed to net secretion in the ileum and colon segments by glucocorticoids. These results are the first to extend the known effects of glucocorticoids into the infancy period.
\end{abstract}

\section{Speculation}

The lack of enhancement in intestinal sodium transport with glucocorticoids in the suckling rat may suggest a maturational phenomenon. It is possible that a steroid sensitive mechanism in the adult animal intestine has not yet appeared in the suckling intestine.

Parenteral administration of glucocorticoids to adult rats has been shown to stimulate sodium and water absorption and potassium secretion in jejunum, ileum, and colon $(1,2)$. The maturation of the suckling rat intestine has been demonstrated to have a glucocorticoid-sensitive period during the third wk of life (7). Maturation of intestinal sucrase and maltase appears to be dependent on a physiologic rise in plasma corticosterone level, which occurs on day 14 of life (5). In addition, glucocorticoids given before this time hasten the intestinal maturation of these enzymes (6). To define the functional role of glucocorticoids on intestinal transport, the current studies were designed. An in vivo single pass perfusion technique was used to determine normal salt, water, and glucose absorption in the suckling period and the effect of methylprednisolone on this maturation.

\section{MATERIALS AND METHODS}

Pregnant Sprague-Dawley rats were obtained from Harlan Industries (Indianapolis, IN). After birth, rat pups were distributed among mothers to maintain litter size at seven to nine pups until the time of the study. Animals were raised under usual laboratory conditions. Methylprednisolone (Solu Medrol, UpJohn) $30 \mathrm{mg} / \mathrm{kg}$ per day was given as a daily intraperitoneal injection on days 11 , 12, 13. The last injection was given $15 \mathrm{~h}$ before perfusion. Control animals were similarily injected with an equal volume of saline. At the time of study (14th day of life), unfasted rats were anesthetized with intraperitoneal injection of an ethylurea-phenobarbital mixture. After opening the abdominal cavity, 15-20 cm segments of jejunum, ileum, and the entire colon excluding the cecum were isolated, cannulated, flushed with $20 \mathrm{ml}$ of warm normal saline and then with $20-30 \mathrm{ml}$ of air. The jejunal segments extended from a point just distal to the ligament of Treitz to $15-20 \mathrm{~cm}$ aborad. The ileum segment extended from the ileocecal valve to $15-20 \mathrm{~cm}$ orad. The colon segment included the entire colon. The can. !ulated segments were then returned to the abdominal cavity. Body temperature of the rats was maintained at $36-37^{\circ} \mathrm{C}$ at all time during perfusion. The cannulated segments were perfused in situ with solutions containing per liter: 115 mmoles sodium chloride, 25 mmoles sodium bicarbonate, 5 mmoles potassium chloride, and $30 \mathrm{mg}$ phenol red (as a nonabsorable marker for volume changes) with $\mathrm{pH}$ adjusted to 7.0 with $0.1 \mathrm{~N}$ sodium hydroxide. A second group of animals was perfused with an identical solution, but with $20 \mathrm{mM}$ D-glucose added to the perfusion fluid. The osmolalities of the solutions were 280 and 300 milliosm $/ \mathrm{kg}$ respectively. After the start of perfusion, a $30-\mathrm{min}$ period was allowed for attainment of steady state conditions. Perfusates were then collected during the next three consecutive 20 -min periods. At the end of the perfusion periods, the perfused segments were stripped from the mesentery and wet weights were determined after expressing the contents gently with forefingers. The segments were then dried in a vacuum oven at $95^{\circ} \mathrm{C}$ for $24 \mathrm{~h}$ and the dry weight was determined. Phenol red in the perfusion solutions and perfusates was determined by Spectro-photometer with a previously described method (11). Previous recovery studies of phenol red in the suckling rats showed $\sim 97-98 \%$ recovery of total phenol red perfused $(11,13)$. Sodium and potassium concentrations were determined with a flame photometer (Instrumentation Labıratory, Inc.). Glucose concentrations were determined using glucose oxidase method (Statzyme Glucose, Worthington Diagnostics).

Disappearance of sodium, potassium or glucose from the lumen was taken to indicate net absorption (positive values) and addition to the luminal fluid was taken to indicate secretion (negative values). The calculations are shown below:

Net $\mathrm{Na}$ transport $\mu$ moles $/ 20 \mathrm{~min}=\mathrm{V}_{\mathrm{i}}\left[\mathrm{Na}_{\mathrm{i}}-\left(\mathrm{Na}_{\mathrm{f}}\right)(\mathrm{PRi} / \mathrm{PRf})\right]$

Where $\mathrm{V}$ is volume perfused in each segment in $\mathrm{ml} / 20 \mathrm{mins} ; \mathrm{Na}$ is total concentration of $\mathrm{Na}$ as $\mu$ moles/ml; $\mathrm{PR}$ is phenol red concentration in $\mu \mathrm{g} / \mathrm{ml}$. Subscripts $\mathrm{i}$ and $\mathrm{f}$ refer to initial values (i) in the perfusion fluid before perfusion and in the perfusate collected (f), respectively. Net glucose and potassium transport was calculated in a similar manner. Net water transport was determined as follows:

$$
\text { New water transport } \mathrm{ml} / 20 \mathrm{~min}=\mathrm{Vi}(\mathrm{l}-\mathrm{PRi} / \mathrm{PRf})
$$

Absorption rates at 20 -min periods did not vary more than $20 \%$ within each rat indicating a steady state. They were added to obtain amount absorbed per $h$. In order to compare transport rates in segments that varied somewhat in length and weight, the quantities transported were expressed per unit dry weight. This transport rate indicated "absorptive specific activity" of the perfused segment. 
Statistical analysis. The unpaired Student's $t$ test was used for statistical comparison of differences between mean values obtained for the rats of control and steroid injected groups. A $P$ value (8) of less than 0.05 was considered to indicate a statistically significant difference between two mean values.

\section{RESULTS}

Mean body weights and measurements of the perfused jejunum, ileum, and colon in suckling (14-day-old) rats of both steroidinjected and control groups are shown in Table 1. Mean body weight in steroid-treated group were significantly less than corresponding mean values in control. Similar observation was noted in a previous study (15). Measurements of the intestinal segments were similar in both groups.

Effect of glucocorticoids on sodium absorption. Net sodium absorption from jejunum, ileum, and colon in control and glucocorticoid-treated suckling rats is shown in Table 2. Initial analysis of sodium absorption by group containing glucose in the perfusion fluid and no glucose showed virtually identical sodium absorption; thus, these groups are combined in the table. Methylprednisolone caused significant increase in sodium absorption only in the colon segment $(P<0.01)$. Net sodium absorption in the small intestinal segments were similar in control and steroid-treated rats.

Effect of glucocorticoids on water flow. Net water absorption from each intestinal segment in control and glucocorticoid-treated suckling rats is shown in Table 3 . Again, the presence or absence

Table 1. Body weights and measurement of the intestinal segments in the rats studied

\begin{tabular}{lcc}
\hline \multicolumn{1}{c}{ Rats } & 2 wk control & 2 wk steroid \\
\hline Number studied & 15 & 15 \\
Body weight $(\mathrm{g})$ & $28.5 \pm 1.0$ & $24.4 \pm 0.8^{2}$ \\
Measurements of the & & \\
$\quad$ segments & & \\
Proximal & $20.4 \pm 1.1$ & $16.7 \pm 1.2$ \\
$\quad$ Length (cm) & $64 \pm 0.1$ & $54 \pm 4$ \\
Dry wt (mg) & $3.1 \pm 0.1$ & $3.2 \pm 0.2$ \\
Dry wt (mg/cm) & & \\
Distal & $18.6 \pm 1.2$ & $22.1 \pm 1.0$ \\
Length $(\mathrm{cm})$ & $51 \pm 4$ & $52 \pm 3$ \\
Dry wt $(\mathrm{mg})$ & $2.7 \pm 0.1$ & $2.4 \pm 0.2$ \\
Dry wt $(\mathrm{mg} / \mathrm{cm})$ & & \\
Colon & $3.5 \pm 0.1$ & $3.7 \pm 0.1$ \\
$\quad$ Length $(\mathrm{cm})$ & $10 \pm 1$ & $11 \pm 1$ \\
Dry wt $(\mathrm{mg})$ & $2.8 \pm 0.05$ & $2.9 \pm 0.1$ \\
Dry wt $(\mathrm{mg} / \mathrm{cm})$ & & \\
\hline
\end{tabular}

'Values are mean \pm S.E.

"Mean values in the steroid-treated group is significantly less than corresponding mean value in the control group $P<0.01$.

Table 2. The effect of glucocorticoid administration of net transport of sodium in the intestinal segments of the rats studied ${ }^{1}$

\begin{tabular}{lcccc}
\hline & No. & Proximal & Distal & Colon \\
\hline Suckling control & (13) & $4.0 \pm 0.5$ & $3.8 \pm 0.6$ & $7.9 \pm 2.8$ \\
Suckling steroid & (13) & $3.2 \pm 0.3$ & $3.8 \pm 0.6$ & $19.1 \pm 3.0^{2}$ \\
\hline
\end{tabular}

${ }^{1}$ Results are mmoles/g of dry wt of segment per $h \pm S$.E.

${ }^{2}$ Mean values in the steroid-treated rats are significantly different than corresponding mean values in control rats $P<0.01$.

Table 3. The effect of glucocorticoids on net water transport in the intestinal segment of the rats studied'

\begin{tabular}{lcccc}
\hline & No. & Proximal & Distal & Colon \\
\hline Suckling control & $(13)$ & $25.0 \pm 3.9$ & $23.5 \pm 3.6$ & $94.2 \pm 26.0$ \\
Suckling steroid & $(10)$ & $21.6 \pm 3.1$ & $22.4 \pm 3.8$ & $77.7 \pm 7.3$ \\
\hline
\end{tabular}

' Results are expressed as $\mathrm{ml} / \mathrm{g}$ dry wt of segments per $\mathrm{h} \pm \mathrm{S}$.E.
Table 4. The effect of glucocorticoids on net potassium transport in the intestinal segment of the rats studied

\begin{tabular}{ccccc}
\hline & No. & Proximal & Distal & Colon \\
\hline $\begin{array}{c}\text { Suckling } \\
\text { control }\end{array}$ & $(6)$ & $109.8 \pm 19.0$ & $139.0 \pm 36.0$ & $390.2 \pm 112.7$ \\
$\begin{array}{c}\text { Suckling } \\
\text { steroid }\end{array}$ & $(6)$ & $21.6 \pm 14.9^{2}$ & $-21.4 \pm 47.5^{2}$ & $-225.8 \pm 78.5^{2}$ \\
\hline
\end{tabular}

' Results are expressed in $\mu$ moles/g dry wt of segment per $h \pm$ S.E.

'Mean values in the steroid-treated rats are significantly different than corresponding mean values in the control rats $P<0.01$.

Table 5. The effect of glucocorticoid on net glucose transport in segments of small bowel in the rats studied ${ }^{1}$

\begin{tabular}{lccc}
\hline & No. & Proximal & Distal \\
\hline Suckling control & $(6)$ & $1.8 \pm 0.3$ & $0.7 \pm 0.1$ \\
Suckling steroid & $(6)$ & $1.9 \pm 3.1$ & $3.1 \pm 0.5^{2}$ \\
\hline
\end{tabular}

'Results are mmoles/g dry wt of segment per $\mathrm{h} \pm \mathrm{S}$.E.

${ }^{2}$ Mean values in the steroid-treated rats are significantly different than corresponding mean values in the control rats $P<0.01$.

of glucose in the perfusion fluid had no effect on the net volume of water absorbed and the data from all groups of animals are combined. Methylpredisolone had no effect on net water movement in all segments studied.

Effect of glucocorticoids on potassium absorption. Table 4 shows net potassium transport in the intestinal segments of control and steroid-treated rats. In control suckling rats, potassium absorption occurred from all intestinal segments. In the steroid-treated group, potassium absorption decreased significantly in the jejunal segments and reversed to net secretion in the distal and colon segments.

Effect of glucocorticoids on glucose absorption. Table 5 shows the effect of methylprednisolone on glucose transport. Net glucose absorption in the jejunal segments were significantly greater than corresponding mean values in the ileal segments $(P<0.01)$. In the ileal segments of steroid-treated groups, mean net glucose transport was significantly greater than corresponding mean values in the control segments $(P<0.05)$. In the jejunal segments net glucose transport was similar in both steroid and control groups.

\section{DISCUSSION}

The concentration of total corticosterone in the rat plasma shows a developmental pattern (5). The concentration of total plasma corticosterone is less than $0.5 \mu \mathrm{g} / \mathrm{dl}$ from day 6 through day 12 . By day 17 the concentration reached $5 \mu \mathrm{g} / \mathrm{dl}$. Peak values of plasma levels of corticosterone levels may trigger certain enzymatic changes that are known to occur in both the intestine and liver during the third postnatal $w k$ in the rat. In the absence of this physiologic increase in steroids, enzymatic maturation is delayed (7). In addition, precocious appearance of certain intestinal brush border enzymes such as sucrase occurs with glucocorticoid administration as early as the ninth day of life in the rat (6).

During the same developmental period, maturational changes in intestinal transport of calcium (4), magnesium (10), and zinc (9) also occur. Transport rates of these minerals are several-fold greater in the suckling period compared to the adolescent period. The decrease in transport rates presumably reflect a maturational change in the membrane permeability. This change in permeability coincides with the physiologic rise in serum corticosterone and with maturation of glucocorticoid-dependent enzymes; however, before the present study, the effect of corticosteroids on the transport of water, electrolytes and glucose in the suckling rat has not been known.

Glucocorticoids given to adult rats as methylprednisolone, 30 $\mathrm{mg} / \mathrm{kg}$ of body weight for 3 days, resulted in significant enhancement of water and sodium absorption and potassium secretion in 
segments of small and large intestine. These changes in transport were associated with an increase in potential differences and $\mathrm{Na}$ K-ATPase activity in all intestinal segments (2).

Binder (1) showed that a second glucocorticoid, dexamethasone, given parenterally for 3 days increased water and sodium absorption and potassium secretion in adult rat colon. Again, potential difference and Na-K-ATPase activity were increased. Binder showed increasing colonic response with increasing dexamethasone dosage, with initiation of changes within $3 \mathrm{~h}$ of the steroid and persisting for $24 \mathrm{~h}$. Because the colon was sensitive to very low dexamethasone dose, the hypothesis has been suggested that glucocorticoids play a physiologic role in colonic (and perhaps small intestinal) salt and water transport (3).

The present study demonstrated that methylprednisolone enhanced sodium absorption in the colon of suckling rats. Suckling rat colon responded similarily to adult colon with respect to sodium absorption; however, there was no enhancement of sodium absorption in response to methylprednisolone administered on days 11 through 13 in segments of the small intestine. This is in contrast to the significant enhancement of sodium absorption in small intestinal segments of adult rats (2). The lack of response in sodium transport in the small intestine of the suckling rat would suggest a maturational process. It is possible that a steroid-sensitive mechanism in the adult animal intestine has not yet appeared in the suckling intestine. In support of this postulate is the recent observation of a decrease in the specific activity of Na-K-ATPase in the small intestine of suckling rabbits compared to adult rabbits. This decrease in Na-K-ATPase activity in the suckling rabbits was associated with a decrease in glucose-coupled sodium transport compared to corresponding transport rates in adult rabbits (12). The increase in sodium absorption in the colon is independent of water absorption, as there is no enhancement of water in any segment with steroid during the suckling period. This finding is similar to a previous study in which net water transport did not follow the net absorption of sodium, chloride and bicarbonate in the suckling rat (14).

The effect of methylprednisolone on potassium flux in the suckling period is similar to the effect previously shown in adult rats (2). Charney et al. (2) has shown that potassium secretion in all segments increases with glucocorticoids, with greatest effect in the ileum and colon. In the present study, net absorption of potassium in control suckling rats was several-fold greater than values obtained by Charney under similar experimental conditions in adult rats with steroids; this absorption decreased dramatically in the jejunum and actually reversed to secretion in the distal small intestine and colon segments.
The effect of methylprednisolone on intestinal glucose transport was similar to that seen in adult rats (2). Glucose transport was significantly enhanced only in the ileal segment. There was no difference between net glucose transport in the jejunal segments of control and steroid treated suckling rats.

The present study extends to the suckling period the previously shown effect of glucocorticoids on sodium transport in adult rat colon; however, no effect on sodium transport in the small bowel could be demonstrated. Glucocorticoid effect on potassium secretion and on glucose absorption also appear to be similar in the suckling and adult rat.

\section{REFERENCES AND NOTES}

1. Binder, H. J.: Effects of dexamethasone on electrolyte transport in the large intestine of the rat. Gastroenterology. $75: 212$ (1978).

2. Charney, A. N.. Kinsey. M. D., Myers, L., and Giannella, R. A.: Na+ - K+ activated adenosine triphosphatase and intestinal electrolyte transport. J. Clin. Invest., 56: 653 (1975).

3. Field. M.: Corticosteroids, Na. K-ATPase and intestinal water and electrolyte transport. Gastroenterology, 75: 317 (1978).

4. Ghishan. F. K.. Jenkins. J. T., and Younoszai. K. M.: Maturation of calcium transport in the rat small and large intestine. J. Nutr.. 110: 1622 (1980).

5. Henning. S. J.: Plasma concentrations of total and free corticosterone during development in the rat. Am. J. Physiol.. 2.35(5): E451 (1978).

6. Henning. S. J.. Helman, T. A., and Kretchmer, N.: Studies on normal and precocious appearance of jejunal sucrase in suckling rats. Biol. Neonate., 26: 249 (1975).

7. Henning. S. J. and Sims, J. M.: Delineation of the glucocorticoid-sensitive period of intestinal development in the rat. Endocrinology. 104: 1158 (1979).

8. Huntsberger. D. V. and Leaverton, P. E.: Statistical inference in the biomedical sciences. In: D. V. Huntsberger and P. E. Leaverton. Eds., (Allyn and Bacon. Inc., Boston. MA, 1970).

9. Meneely, R. and Ghishan. F. K.: In vivo intestinal zinc transport in rats: Normal and protein malnourished. Clin. Res., 28: 821 A (1980).

10. Meneely, R.. Leeper. L.. and Ghishan. F. K.: Intestinal maturation: Magnesium transport. Pediatr. Res.. 16: 295 (1982).

11. Schedl. H. P. and Clifton. J. A.: Small intestinal absorption of steroids. Gastroenterology, 41: 491 (1961).

12. Shepherd. R. W.. Hamilton. J. R.. and Gall. D. G.: The postnatal development of sodium transport in the proximal small intestine of the rabbit. Pediatr. Res., 14: $250(1980)$.

13. Younoszai. M. K.. Sapario, R. S.. and Laughlin. M.: Maturation of jejunum and ileum in rats. J. Clin. Invest., 62: 271 (1978).

14. Younoszai. M. K.: In vivo transport of water and electrolytes in the infant rat intestine. Proc. Soc. Exp. Biol. Med.. 160: 192 (1979).

15. Younoszai, M. K. and Ghishan. F. K.: In vivo intestinal calcium absorption in infant rats: Influence of methylprednisolone and vitamin D. Proc. Soc. Exp. Biol. Med.. 158: 174 (1978).

16. Requests for reprints should be addressed to: Dr. Fayez K. Ghishan, Vanderbilt Medical Center. Pediatric/Gastroenterology. Nashville. Tennessee 37232.

17. Received for publication August 19, 1981.

18. Accepted for publication March 10, 1982. 